\title{
El glifosato afecta negativamente a los espermatozoides humanos: evidencia in vitro
}

\section{Glyphosate Negatively Affects Human Sperm: in vitro evidence}

\author{
Walter D. Cardona Maya ${ }^{1}$ \\ 1 Departamento de Microbiología y Parasitología, Facultad de \\ Medicina, Universidad de Antioquia, Medellín, Colombia \\ Urol Colomb 2020;29:96-98.
}

\begin{abstract}
Address for correspondence Walter D. Cardona Maya, PhD, Departamento de Microbiología y Parasitología, Facultad de Medicina, Universidad de Antioquia, Carrera 53 \# 61-30, Laboratorio 534, Medellín, Colombia (e-mail: wdario.cardona@udea.edu.co).
\end{abstract}

\section{Resumen \\ Palabras claves \\ - Espermatozoides \\ - fertilidad \\ - glifosato \\ - Calidad seminal}

Determinar el efecto del glifosato sobre la calidad seminal en humanos a través de una revisión sistemática. Se realizó una búsqueda de la literatura en dos bases de datos (Pubmed y Scopus) de los terminos glyphosate/gliphosate/Roundup/yerbimat y sperm/“male reproductive tract”. Los criterios de selección permitieron analizar tres artículos sobre el efecto del glifosato sobre los espermatoozides humanos. Se observó un efecto de negativo del glifosato sobre los espermatoozides humanos (movilidad, actividad mitocondrial y DNA). Aunque son pocos los artículos que evalúan el efecto del glifosfato sobre la calidad seminal, todos concluyen en sus repercusiones negativas. Investigaciones sobre el tema se requieren especialmente ahora que el Gobierno Nacional pretende implementar su uso.

To determine the effect of glyphosate on seminal quality in humans through a systematic review. Two databases (Pubmed and Scopus) were searched for potentially relevant publications about glyphosate/gliphosate/Roundup/yerbimat and sperm/“male reproductive tract". Selection criteria allowed analyzing three articles on the effect of glyphosate on human spermatozoa. An adverse effect of glyphosate was observed on human spermatozoa (mobility, mitochondrial activity, and DNA). Although few articles evaluate the effect of glyphosate on seminal quality, all conclude in its negative repercussions. Research on the subject is especially needed now that the National Government intends to implement its use.

\section{Introducción}

La fertilidad es un pilar importante del desarrollo social, y afecta tanto a los individuos como a las comunidades; errores en la lotería reproductiva y la imposibilidad de embarazarse $\mathrm{y}$ tener descendencia, repercuten no solo en la salud mental de la pareja sino también en la vida cotidiana, laboral y académica de quienes lo padecen. ${ }^{1}$ Se considera que el hombre es el responsable de como mínimo el 50\% de los casos de consulta por infertilidad y una de las alteraciones más comunes son las de los parámetros seminales convencionales y funcionales que incluyen la movilidad, la viabilidad, la concentración, la morfología, el potencial de membrana mitocondrial y la compactación del ADN. ${ }^{2-5}$

En un país como Colombia donde existen múltiples problemas sociales y que sufre un proceso de transformación en el postconflicto, las decisiones políticas que afectan a la comunidad en general, entre las que se incluye la aspersión de los cultivos ilícitos de coca con glifosato, son objeto de discusiones sociales y económicas received

March 27, 2019

accepted

July 26, 2019
DOI https://doi.org/

10.1055/s-0039-1696699.

ISSN 0120-789X.

e ISSN 2027-0119.
Copyright (c) 2020, Sociedad Colombiana License terms de Urología. Publicado por Thieme Revinter Publicações Ltda., Rio de Janeiro, Brazil. Todos los derechos reservados. 
principalmente, omitiendo en la mayoría de las ocasiones, la mirada académica y la investigación de aspectos que pueden afectar la salud humana, discusión que hemos podido ver y escuchar en las ultimas semanas en todos los medios de comunicación. Generalmente, esa discusión se basa principalmente, en las afecciones de la salud más comunes o con efectos en aspectos de la salud observables a corto plazo, como las alteraciones respiratorias, las dermatológicas y perdidas del embarazo. ${ }^{6}$ Sin embargo, es importante evaluar otras posibles alteraciones sobre la salud que podrían afectar la calidad de vida en el futuro cercano, por ejemplo, dando una mirada microscópica a los gametos responsables de sustentar la vida; por tanto, el propósito de esta revisión sistemática de la literatura, fue determinar el efecto del glifosato sobre la calidad seminal en humanos.

\section{Métodos}

Se realizó una búsqueda de la literatura publicada sobre los espermatozoides y el glifosato en las bases de datos Pubmed y Scopus, sin restricción por fecha de publicación. Se incluyeron el total de artículos publicados (artículos originales, revisiones del tema e investigaciones experimentales), y de forma adicional se revisó la bibliografía reportada en cada artículo con el propósito de incrementar los artículos a analizar.

\section{Resultados}

La búsqueda realizada en 14 de marzo de 2019 mediante los términos seleccionados (glyphosate or gliphosate or Roundup or yerbimat) and (sperm or "male reproductive tract"), arrojó un total de 54 publicaciones, 28 en Pubmed y 27 en Scopus, siendo que 23 fueron eliminadas por estar duplicadas. Finalmente, se seleccionaron 3 publicaciones que específicamente evalúan el efecto del glifosato sobre los espermatozoides humanos.

Los tres artículos publicados sobre glifosato y el efecto in vitro sobre los espermatozoides humanos ${ }^{7-9}$ evidencian una disminución de la movilidad progresiva a la hora de un $17,4 \%$; a las tres horas de un $17,7 \%$ y una disminución de la actividad mitocondrial al $45,5 \%$ y un aumento del daño del DNA de 5,12\% (-Figura 1). La movilidad espermática fue determinada mediante microscopía convencional, la fragmentación del DNA utilizando el método de dispersión de la cromatina espermática (Halosperm ${ }^{\circledR}$ ) cuantificando el halo después de procesar los espermatozoides, mientras que la actividad mitocondiral mediante la coloración con el colorante mitocondrial (Mitotracker), se une a la mitocodnria dependiendo del potencial de membrana.

\section{Discusión}

Los tres artículos experimentales en los cuales exponen espermatozoides humanos libres de plasma seminal con glifosato, demuestran que el glifosato afecta negativamente la movilidad y algunas características funcionales espermáticas como el potencial mitocondrial y el ADN. Por lo tanto, se podría postular que ese mismo efecto sería el que sucede después de su acumulación en el cuerpo y posterior a entrar en contacto con el glifosato por una aspersión aérea.

El análisis seminal es una prueba que permite valorar el estado fértil de un hombre y en la cual se cuantifican los parámetros seminales convencionales ${ }^{2}$ y funcionales. $^{10}$

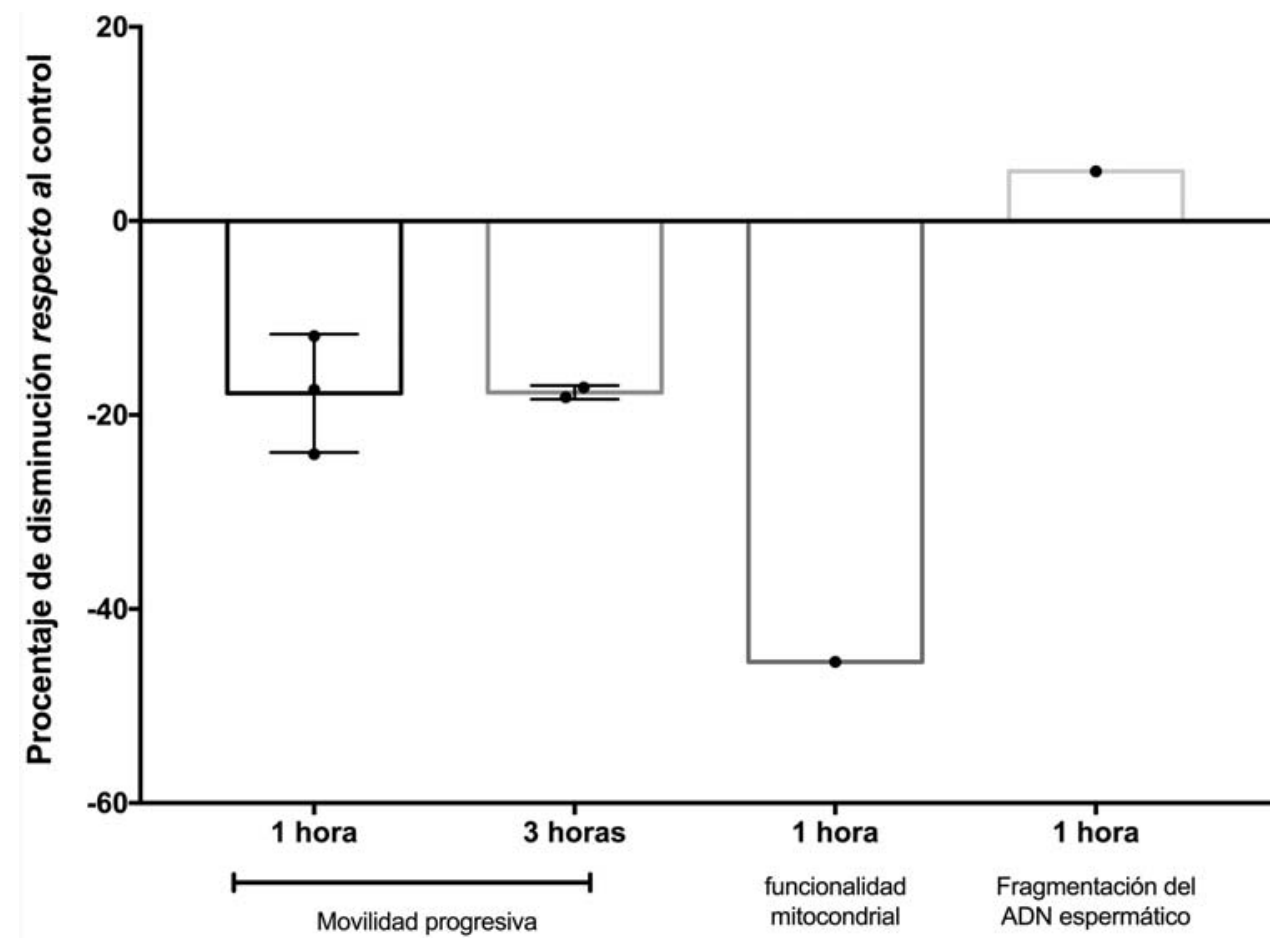

Fig. 1. Consolidación de los resultados sobre el efecto del glifosato sobre los espermatozoides humanos. 
Cuando el resultado de un espermogrma está alterado, con valores debajo del limite inferior de referencia, ${ }^{11}$ se asume que la posibilidad de lograr un embarazo es menor. Por lo tanto, la evidencia existente sobre los efectos negativos del glifosato sobre la parámetros seminales permiten sugerir un efecto negativo sobre la fertilidad en humanos.

Se requieren estudios que evalúen el efecto de la aspersión de glifosfato sobre la fertilidad masculina en la población colombiana, sin desmeritar que esos estudios también se deben enfocar en evaluar el efecto del herbicida en la reproducción de la fauna presente en los sitios de fumigación. La salud humana, definida por la Organización Mundial de la Salud "un estado de completo bienestar físico, mental y social, y no solamente la ausencia de afecciones o enfermedades"12 involucra que todo aquello que atente contra el entorno en el que se desenvuelve el individuo puede repercutir sobre su salud, desde esa perspectiva, se requiere un análisis completo de los efectos de la aspersión de glifosfato sobre la salud humana como herramienta de reordenamiento de las políticas públicas de un país que debe concentrar sus esfuerzos en mejorar la calidad de vida de una población arduamente afectada por la guerra.

\section{Conclusiones}

En conclusión, si bien la información existente en ensayos en humanos es escasa, la evidencia existente demuestra que el uso del glifosato afecta negativamente la calidad seminal in vitro, seguramente ese mismo fenómeno ocurre in vivo. Por lo tanto, el uso de este herbicida debe tener un control muy estricto si existe la mínima sospecha de riesgo de contacto con los humanos.

\section{Responsabilidades Éticas}

Protección de personas y animales. Los autores declaran que para esta investigación no se han realizado experimentos en seres humanos ni en animales.

Confidencialidad de los datos. Los autores declaran que en este artículo no aparecen datos de pacientes.
Derecho a la privacidad y consentimiento informado. Los autores han obtenido el consentimiento informado de los pacientes y/o sujetos referidos en el artículo. Este documento obra en poder del autor de correspondencia.

Conflicto de Intereses

Los autores declaran no tener ningún conflicto de intereses.

\section{Referencias}

1 Culley L, Hudson N, Lohan M. Where are all the men? The marginalization of men in social scientific research on infertility. Reprod Biomed Online 2013;27(03):225-235

2 de los Ríos J, Cardona WD, Berdugo JA, et al. [Sperm parameters in 113 subjects after recent fatherhood did not correlate with WHO standards]. Arch Esp Urol 2004;57(02):147-152

3 Mayorga Torres JM, Peña B, Cadavid AP, Cardona Maya WD. La importancia clínica del ADN espermático en el análisis seminal cotidiano. Rev Chil Obstet Ginecol 2015;80(03):265-268

4 Mayorga-Torres BJM, Camargo M, Cadavid AP, du Plessis SS, Cardona Maya WD. Are oxidative stress markers associated with unexplained male infertility? Andrologia 2017;49(05):

5 Tamayo Hussein S, Cardona Maya WD. Evaluar el factor masculino mediante un espermograma durante la consulta de infertilidad. Rev Cuba Obstet Ginecol 2017;43(02):

6 Camacho A, Mejía D. The health consequences of aerial spraying illicit crops: The case of Colombia. J Health Econ 2017;54:147-160

7 Yousef MI, Bertheussen K, Ibrahim HZ, Helmi S, Seehy MA, Salem $\mathrm{MH}$. A sensitive sperm-motility test for the assessment of cytotoxic effect of pesticides. JEnviron Sci Health B 1996;31(01):99-115

8 Anifandis G, Amiridis G, Dafopoulos K, et al. The In Vitro Impact of the Herbicide Roundup on Human Sperm Motility and Sperm Mitochondria. Toxics 2017;6(01):E2

9 Anifandis G, Katsanaki K, Lagodonti G, et al. The Effect of Glyphosate on Human Sperm Motility and Sperm DNA Fragmentation. Int J Environ Res Public Health 2018;15(06):E1117

10 Cardona Maya WD, Berdugo Gutiérrez JA, de los Ríos J, Cadavid Jaramillo AP. Functional evaluation of sperm in Colombian fertile men. Arch Esp Urol 2007;60(07):827-831

11 Cardona Maya W. [World Health Organization manual for the processing of human semen-2010]. Actas Urol Esp 2010;34(07): 577-578

12 Organización Mundial de la Salud. https://www.who.int/es/ about/who-we-are/frequently-asked-questions [updated 22 de marzo de 2019] 